\title{
CONCEPTO Y NATURALEZA DEL TESTAMENTO
}

\author{
José Manuel Fernández Hierro
}

\section{Concepto}

El testamento es la institución clave del derecho sucesorio: ciertamente la sucesión puede regularse por la ley y el testamento también tendrá que respetar los límites legales, pero como institución propia del derecho civil, y concretamente del derecho de sucesiones, la que resalta es la del testamento.

Una definición clásica es la de UlPIANO ${ }^{1}$ según la cual testamentum es mentis nostrae iusta contestatio, in id sollemniter factum ut post mortem nostram valeat. Se ha señalado que tanto la definición de Modestino como la de UlPIANO, queriendo abarcar la hetereogeniedad de disposiciones que el testamento puede contener son imprecisas ${ }^{2}$, olvidándose, por ejemplo de algo tan esencial como la institución de heredero, y en definitiva se ha dicho el testamento romano es «el acto unilateral y personalísimo, solemne y revocable en el que se contiene necesariamente la institución de uno o varios herederos y puede ordenarse además otras disposiciones para que todas tengan efecto después de la muerte del testador» ${ }^{3}$.

El derecho romano admitió diversas formas de testamentos, las cuales fueron evolucionando a lo largo de la historia: en el antiguo ius civile se admitía el testamento calatis comitiis, el testamento in procintu y el per aes et libram; el primero ante los comicios, el segundo ante el pueblo reunido en unidades militares, y el tercero, que es el que sobrevivió de los tres, con el rito de la balanza y el metal similar al existente para crear obligaciones o transmitir el dominio ${ }^{4}$.

\footnotetext{
Regl., 1.

2 ARIas Ramos, Derecho Romano, Madrid 1954, tomo 1, p. 997.

3 ARIAS Ramos, obra citada, p. 998.

4 D'ors, Derecho privado romano, Pamplona 1986, p. 329.
} 
El derecho justinianeo cambió las formas del testamento en dos grupos, denominados testamento privado y testamento público.

El primero podía ser oral o escrito pero siempre exigía siete testigos voluntarios y capaces y la unidad de acto: en el escrito además del texto del testamento y de la firma del testador si era ológrafo, se necesitaba la subscriptio de cada testigo.

En cambio el testamento público era efectuado ante una determinada autoridad: que podía ser la judicial o municipal si se tratara del testamentus apud acta conditum y los archivos imperiales si se trataba del testamentu principii oblata; todo ello sin contar con determinadas formas especiales de testar como podían ser el testamento en tiempo de epidemia y el testamento del analfabeto o el testamento militar.

En la Edad Media la institución de la primogenitura cobra más trascendencia, ligada al concepto del feudalismo y a la necesidad de mantener el feudo, siendo la primogenitura, como señala SÁNCHEZ RoMÁN ${ }^{5}$, la poderosa palanca de la sucesión feudal para conseguir la transformación de la aristocracia de funcionarios en nobleza de nacimiento.

Otra característica del derecho medieval es el principio de la prioridad masculinidad, al menos en la situación legítima.

Pero las ideas anejas al feudalismo propiamente dicho continúan en la época de la monarquía absoluta por medio de las vinculaciones, mayorazgo y por los fidecomisos de primogenitura, Mayorazgo y señoríos, que se extendieron fuera del ámbito nobiliario, puesto que personas enriquecidas querían precisamente lograr su acceso a la nobleza por medio, o con la ayuda de tales vinculaciones.

En cualquier caso hay que recalcar que Las Partidas recogen, como es sabido los criterios del derecho romano y por eso admiten fundamentalmente los criterios del derecho romano y no los derechos germánicos que se habían introducido en los fueros municipales.

Todo ello acabá con la Revolución Francesa que volvió al régimen igualitario del derecho romano basado en los principios de sucesión por parte de los hijos sin prioridad en atención a los conceptos de masculinidad ni de primogenitura. El Código de Napoleón se basó en tales principios, abriendo además la sucesión a los hijos naturales.

Pero en cuanto al testamento, se tenía el temor de que el abrir la mano a una amplia libertad de testar volviera a dar paso a la instauración por

5 Estudios de Derecho Civil, tomo 6. ${ }^{\circ}$, vol. 1. ${ }^{\circ}$, p. 146. Aunque el propio autor reconoce más adelante (Ibidem, p. 163) que tanto el ordenamiento de las Cortes de Nájera como el Fuero Viejo de Castilla señalan, de manera acorde con numerosos fueros municipales, la sucesión forzosa de los hijos por partes iguales sin diferencia entre ellos por edad ni sexo, con la excepción del derecho del primogénito a las armas y caballo de su padre. 
tal vía de los principios de primogenitura y mayorazgo, por lo cual se establecieron una serie de limitaciones a la facultad de testar.

El artículo 667 del Código Civil señala que el acto por el cual una persona dispone para después de su muerte de todos sus bienes o de parte de ellos, se llama testamento.

Se ha criticado por la doctrina el aludido precepto, señalando que un código no tiene por qué contener una definición del testamento, pero la definición contenida en nuestro ordenamiento jurídico no es ni mucho menos única: también la tienen el artículo 587 del Código Italiano ${ }^{6}$, el artículo 2.179.1. ${ }^{\circ}$ del Código Portugués ${ }^{7}$ y el artículo 1.295 del Mexicano ${ }^{8}$, como el artículo 895 del Código Francés ${ }^{9}$, o el $§ 552$ del Código Austríaco, entre otros, si bien no la contienen algunos modernos como el suizo ${ }^{10}$.

Independientemente de la procedencia o no de que un código contenga una definición (apunta acertadamente AlBALADEJo ${ }^{11}$ ) que nada cambiaría si el artículo no existiera) es cierto que la definición que el Código Civil español recoge es imperfecta por varios motivos - no alude a la institución de heredero, ni a las disposiciones no patrimoniales

6 Testamento. Il testamento è un atto revocabile con il quale taluno dispone, per il tempo in cui avrà cessato di vivere, di tutte le proprie sostanze o di parte di esse.

Y de acuerdo con el antiguo Código Italiano, el testamento es un acto unilateral, solemne y revocable, mediante el que alguno, según las reglas establecidas por la Ley, dispone para después que haya cesado de vivir de todo o parte de su patrimonio en favor de una o más personas.

7 Diz-se testamento o acto unilateral e revogável pelo qual uma pessoa dispoe, para depois da morte, de todos os seus bens ou de parte deles.

8 Testamento es un acto personalísimo, revocable y libre, por el cual una persona capaz dispone de sus bienes y derechos y declara o cumple deberes para después de su muerte.

${ }^{9}$ Le testament est un acte par lequel le testateur dispone, pour le temps où il n'existera plus, de tout ou partie de ses biens et qui'il peut révoquer.

${ }^{10}$ Si bien el artículo 481 del Código Civil Suizo (en parecido sentido el 1.939 del B.G.B.) señala:

«1. Les dispositions par testament ou pacte successoral peuvent comprendre tout ou partie du patrimoine, dans les limites de la quotité disponible.

2. Les biens dont le défunt n'a point disposé passent à ses héritiers légaux».

Y previamente el artículo 467 del Código Suizo indica que:

«Toute personne capable de discernement et âgée de 18 ans révolus a la faculté de disposer de ses biens par testament, dans les limites et selon les formes établies par la loi».

También en Inglaterra la Wills Act, 1837, s. 3, señala:

«All real Estate and all personal estate which he shall be entitled to, either at law or in equity at the time of his death, and which, if not so... disposed of, would devolve upon the heirat-low or the customary heir of him, or if he became entitled by descent of his ancester, or upon his executor or administrator».

11 «Comentarios a los artículos 657 a 693 del Código Civil» en Comentarios al Código Civil y compilaciones forales dirigidos por Manuel AlbaladeJo, Editorial Edersa, Madrid 1990, p. 97. 
recogidas en el testamento, por ejemplo- pero admitidas éstas también hay que reconocer, a favor de la definición legal tan criticada (se ha dicho por SÁNCHEZ RoMÁn que el artículo 667 no es completo, ni exacto, ni útil) su claridad y simplicidad superior a la mayoría de las definiciones más científicas que la doctrina ha elaborado.

Según JORDANO BAREA ${ }^{12}$ hay tres concepciones fundamentales del testamento: 1) en sentido formal; 2) en sentido sustancial y amplio; 3) y en sentido sustancial y estricto.

Y sigue señalando que según la primera concepción «el testamento no es un negocio jurídico, sino una simple forma documental acta para acoger en sí la múltiple variedad de los negocios a causa de muerte, admitido por el Ordenamiento. Más que un determinado contenido, lo que caracteriza al testamento es una forma».

En sentido sustancial y amplio se concibe el testamento, según el mismo autor, como un negocio negocial a causa de muerte, carácter general y contenido variable, patrimonial y no patrimonial.

Y finalmente, en el tercero de los sentidos, sustancial y estricto es, para JORDANO BAREA, el cual el negocio jurídico unilateral y no recepticio, mortis causa típico por el cual se dispone el patrimonio para el tiempo posterior a la muerte.

Sigue señalando que en nuestro derecho el testamento es «el negocio jurídico unilateral, unipersonal, personalísimo, no recepticio, formal o solemne, normalmente gratuito que opera una institución de heredero legado».

Para TRAVIESAS ${ }^{13}$ el testamento es el medio de que se sirve el causante para regular su sucesión hereditaria. Y señala que con este término se designa tanto la voluntad del causante como el documento que contiene su declaración de voluntad.

Según Royo MARTínez ${ }^{14}$ el testamento «es un negocio jurídico unilateral, formal o solemne, personalísimo e irrevocable, por el que una persona dicta disposiciones, especialmente patrimoniales para después de su muerte».

AlBALADEJo ha definido al testamento ${ }^{15}$ como el negocio solemne o formal por el que unilateralmente una persona sola (carácter unipersonal) establece ella misma (carácter personalísimo) para después de su

12 Comentarios al Código Civil, publicado por el Ministerio de Justicia y dirigido por Cándido Paz: Ares Rodríguez, Rodrigo Bercovitz, Díez Picazo, y Salvador Cordech, tomo I, p. 1678.

13 «El testamento», en Revista de Derecho Privado, 1935, p. 99.

14 Derecho sucesorio mortis causa, Sevilla 1951, p. 72.

15 Obra citada, p. 101. 
muerte las disposiciones (patrimoniales o no) que le competa pudiendo siempre revocarlas.

Ahora bien, tales características no pueden admitirse sin discusión o contradicción, y atendiendo a todo ello podíamos decir con carácter de más generalidad que el testamento es el acto por el que una (o varias en los supuestos que la ley admite), persona establece las disposiciones que desee para después de su muerte, disposiciones que siempre podrá revocarlas cumpliendo los trámites legales.

El Tribunal Supremo tras señalar que el artículo 667 del Código Civil es «un artículo genérico definidor y mejor aún conceptualmente limitador» pero nada más ${ }^{16}$, y que el testamento es esencialmente un acto dispositivo de bienes o derechos que se disponen para después de la muerte del causante y concluye señalando que siempre es necesario la esencia de la disposición «mortis causa» en sus palabras ${ }^{17}$ : siendo de resaltar la diferenciación que ha efectuado el Tribunal Supremo entre la declaración de voluntad seria destinada a producir efectos jurídicos del testamento y los meros consejos del testador que no son vinculantes, ratificando que la forma es esencial al acto testamentario ${ }^{18}$.

Y en cuanto a la definición de testamento el Tribunal Supremo, ha entendido que «es un acto o negocio jurídico solemne, en principio, unilateral y esencialmente revocable, otorgado por persona capaz con la intención seriamente declarada de producir, para después de la muerte de su autor, consecuencias eficaces en derecho, y, por ello, es obvio que las admoniciones, ruegos o consejos, no elevados por el de de cuius al rango de normas de la delación hereditaria y de obligado acatamiento para los herederos, no producen acciones viables en justicia en orden a su estricta ejecución, ya que de otro modo se equipararía el mero deseo de índole sentimental o efectivo con las disposiciones testamentarias en sentido propio ${ }^{19}{ }$.

Se ha polemizado sobre la naturaleza patrimonial o no del contenido del testamento.

Así en cuanto a la posibilidad de que las resoluciones no patrimoniales puedan consignarse en un testamento mantiene JORDANO BAREA ${ }^{20}$ :

«1) Pertenecen a la sustancia de éste; o 2) constituyen, más bien, un acto segundario: a) adjunto al testamento; o b) asimilado a él por razón de estar sometido a los mismos requisitos de forma. Pero el TS no se

\footnotetext{
6 S. 2 de junio de 1987, Ar. 4204.

7 S. 8 de julio de 1940, Ar. 689.

18 S. 10 de julio de 1944, Ar. 911.

19 S. 24 de noviembre de 1958, Ar. 3.800.

20 Obra citada, p. 1679.
} 
pronuncia expresamente en uno u otro sentido, aunque parece mostrar inclinación hacia la solución 2. Por nuestra parte, nos decidimos resueltamente hacia esa misma solución, en la variante sub b). Acoger la solución 1 implicaría seguir una concepción ecléctica del testamento, cifrada en combinar o conciliar las dos concepciones del mismo en sentido sustancial, amplio y estricto, tal como hace CicU.»

Precisamente $\mathrm{CICU}^{21}$ hace referencia a los esfuerzos de la doctrina para comprender dentro del testamento los actos que no fueron de disposición de bienes bajo el imperio del restrictivo Código italiano de 1865, y que se debía entender como testamento cualquier disposición de acto de última voluntad, a semejanza de las disposiciones patrimoniales, aunque - continúa - no es fácil admitir que la voluntad privada pueda constituir toda clase de relaciones jurídicas después de la muerte, con independencia de su contenido no patrimonial ${ }^{22}$; y pone el ejemplo del testador que dispone que su perro sea mantenido a la manera que lo hacía él, y señala que para que esa determinación tenga tutela jurídica es menester que haya alguna persona obligada a la manutención y otra persona que tenga contra esta acción por incumplimiento, y concluye que la forma de conseguirlo sería un modus o condición resolutoria a cargo del heredero legatario, ya que de otra forma tal deseo de contenido no patrimonial no tendría sanción por parte del derecho.

Señala AlBaladeJO ${ }^{23}$ cómo la doctrina se encuentra dividida de quienes de acuerdo con la letra del código no es de esencia al testamento la disposición de bienes, aun cuando casi todo testamento lo contenga, y que, por tanto, no es necesario que los actos de última voluntad que contengan disposición de bienes, bastando la voluntad de establecer regulación mortis causa, aunque sea relativa a otros extremos, siempre que sea expresada con las formalidades exigidas por la Ley; y la otra postura en la que, no aceptando lo anterior, se admite que en nuestro ordenamiento jurídico ${ }^{24}$ para

21 Obra citada, pp. 11 y ss.

22 Cicu, El Testamento, Madrid 1959, p. 18.

23 Obra citada, p. 98.

${ }^{24}$ En cuanto a otros ordenamientos el Código Civil italiano indica en el artículo 587-2:

«Le disposizioni di carattere non patrimoniale, che la legge consente siano contenute in un testamento, hanno efficacia, se contenute in un attro che ha la forma del testamento, anche se manchino disposizioni di carattere patrimoniale».

De acuerdo con el artículo 3.607 del Código argentino el testamento es un acto por el que una persona dispone «del todo o parte de sus bienes».

También el artículo $2.179-2 .^{\circ}$ del Civil portugués señala:

«As disposições de carácter não patrimonial que a lei permite inserir no testamento são válidas se fizerem parte de um acto revestido de forma testamentária, ainda que nle não figurem disposições de carácter patrimonial». 
disposiciones que se hagan en testamento, no se exige la disposición de bienes.

Como puede verse, ambas posturas son, en el fondo, coincidentes; pero en mi opinión una interpretación literal del artículo 667 del Código Civil nos llevaría a conclusión diferente de la mantenida por la doctrina. Ciertamente es un artículo atacado del que se ha dicho que no tiene ninguna finalidad, pero no obstante es un precepto del código y si de acuerdo con él, el testamento es un acto por el que se dispone de todos sus bienes o parte de ellos, no parece que con una interpretación literal del mismo al acto que no contenga disposiciones patrimoniales, aún cuando cumpla los demás requisitos que señala la ley para los testamentos, pueda calificarse de tal; pero con una interpretación más abierta, que estimo preferible, y atendiendo a las finalidades perseguidas, no se ve por qué la disposición que contenga sólo decisiones extrapatrimoniales no deba tener el carácter del testamento.

Ciertamente en la mayoría de los casos el testamento contendrá disposiciones de carácter económico y casi estará formado por ellas exclusivamente ${ }^{25}$; pero puede tener otros contenidos como el de reconocimiento de hijo extramatrimonial (artículo 120-1. ${ }^{\circ}$ del Código Civil) o la designación de tutor (artículo 234-3. ${ }^{\circ}$ del Código Civil).

Notemos que en ambos casos se requiere que el reconocimiento o la designación sea efectuado en testamento o acto de última voluntad, y no se ve si nos encontramos con una persona que no quiere tomar ninguna medida sobre sus bienes (por no disponer de ellos o por no conformarse con la sucesión legítima) no pueda indicar el tutor que desea para sus hijos o reconocer a un hijo ${ }^{26}$ extramatrimonial: tal prohibición, además de ser profundamente injusta, vedaría el principio de igualdad contenido en el artículo 14 de la Constitución; con lo cual, en definitiva, estimo que a pesar de la literalidad del texto del artículo 667 cabe que el testamento contenga solamente disposiciones

25 Los llamados testamentos literarios, o éticos, etc., no son testamento en el sentido jurídico de la palabra sino en la mayoría de los casos un resumen de la ideología o de la postura sustentadas por el autor del mismo.

${ }^{26}$ Incidentalmente cabe preguntarse si sería válido a los efectos del reconocimiento el testamento ológrafo o cualquier otro en que no intervenga fedatario público. La duda puede plantearse por la expresión final del inciso primero del artículo 120 cuando alude a otro documento público, que parece presuponer que los anteriores lo son, incluido el testamento, mientras que al aludir a éste no excluye ninguna clase o categoría.

En mi opinión no cabe hacer distingos porque la ley no los efectúa y cualquier clase de testamento sería acto para el reconocimiento de un hijo. 
de carácter no patrimonial, y el contenido del artículo 741 del Código Civil que admite el reconocimiento del hijo en testamento revocado refuerza esta tesis.

La postura del Tribunal Supremo no ha sido unívoca, ya que en algunos fallos ha sostenido que sin disposición de bienes no hay testamento $^{27}$.

Sin embargo, ulteriormente, el propio Tribunal Supremo ha entendido lo contrario ${ }^{28}$ :

«Que el segundo motivo, por el mismo cauce procesal que el anterior, alega la violación por la sentencia del artículo 133 en relación al 667 ambos del Código Civil, por entender el recurrente que no siendo en realidad testamento el que otorgó en 21 de enero de 1955 por no contener disposición de bienes para después de su muerte, ni ninguna otra mortis causa, pues se limita al reconocimiento del hijo, queda reducido a una auténtica manifestación de voluntad ante Notario pero que precisa para su efectividad la aprobación judicial con audiencia del Ministerio Fiscal y al no haberse hecho así carece de eficacia y validez jurídica: y como quiera que la jurisprudencia viene reconociendo como testamentos aquéllos en que expresada la voluntad de testar se determina el reconocimiento de un hijo natural o el nombramiento de tutor, etc.; parece evidente que el de referencia debe calificarse como tal con toda la fuerza que le concede el artículo 741 del Código y no puede prosperar el recurso.»

Tal postura jurisprudencial es absolutamente correcta, porque de no serlo así un hecho tan importante como el reconocimiento de un hijo se vería privado de efecto, con la trascendencia que ello conlleva.

Por todo ello el carácter patrimonial como exigencia del testamento entiendo que no puede ser predicable sin perjuicio de que suela ser el contenido habitual y normal del mismo.

\section{Problemas previos}

Como problemas previos, la existencia del testamento plantea una serie de problemas previos, relacionados con su propia existencia y su admisión, y ligado con lo anterior, pero de una forma tangencial.

27 Ss. 6 de agosto de 1914 y 8 de julio de 1940, Ar. 689, la cual señala «el ser esencialmente el testamento un acto dispositivo de bienes o derechos».

28 S. 22 de diciembre de 1964, Ar. 5.906. 


\section{1. ${ }^{\circ}$ Admisión del testamento}

Como queda dicho, el testamento no tiene razón de ser en los regímenes sucesorios que sólo admiten la ley como forma de regulación de la herencia, no dando margen a la intervención de la voluntad, prácticamente inexistente, el testamento no tiene función de ser.

Pero hay que observar que incluso desde otra óptica se ha podido negar la validez o la necesidad del testamento, y es desde una óptica filosófica social, ya que si se adopta una teoría totalmente socialista la sucesión no tendría razón de ser, al no existir la propiedad privada.

MANRESA $^{29}$ ha mantenido que el testamento es una emanación del derecho de propiedad. Si negamos tal derecho la consecuencia lógica es que el testamento no tendría razón de ser.

Según COVIELLO ${ }^{30}$ el testamento está basado en los instintos naturales del hombre que teniendo una propiedad quiere transmitirla como mejor le agrade, y continúa precisando que si se violaran tales derechos se violarían los instintos humanos si se le prohibiese al hombre disponer como mejor le plazca del fruto de sus trabajos y sus ahorros y que sólo los que niegan el derecho de propiedad individual pueden con fundamento negar el derecho de testar.

La misma tesis mantiene LoSANA ${ }^{31}$ que señala que no se puede admitir sin contradicción la propiedad privada sin reconocer el derecho de sucesión y de testamentifacción.

Habría que matizar las observaciones de la antigua doctrina ya que cuando ésta ha insistido en que el derecho de hacer testamento constituye un estímulo al ahorro y un consuelo para el ciudadano que sabe que sus bienes quedarán en poder de los suyos después de su fallecimiento, habría que atribuir tales cualidades más que al testamento al derecho de sucesión, puesto que lo habitual son las disposiciones legales o similares a éstas; y máxime cuando se piensa en que la familia directa será la beneficiaria de la herencia y ésta sería con pequeñas variantes quien habría de suceder, bien por vía hereditaria, bien con carácter legal e intestato.

Por eso señala $\mathrm{CICU}^{32}$ que la antigua doctrina hablaba de los fundamentos filosóficos y racionales del derecho de testar, pero sería más exacto buscar su fundamento jurídico; aunque sigue señalando que el fundamento del derecho de testar es la propiedad privada.

29 Comentarios al Código Civil Español, tomo V, Madrid 1921, pp. 420 y ss.

30 Corso completo del Diritto delle successioni, citado por TrAVIESAS en «El testamento», Revista de Derecho Privado, 1935, p. 98.

31 Delle successioni testamentarie, citado también por TRAVIESAS, obra citada, p. 98.

32 Obra citada, p. 5. 
Pero se da la paradoja de que incluso en los regímenes que han propugnado una socialización total, y que han tratado de eliminar el derecho de propiedad no han llevado hasta sus últimas consecuencias tal postura negando el derecho de sucesión como parecería lógico: es más, podía ser más fácil luchar contra el derecho de propiedad atacando al derecho de sucesión que viceversa, aunque el sistema exigiera el paso de una generación (tiempo que históricamente es desdeñable). Sin embargo bien por entender que el negar totalmente el derecho de sucesión no sería aceptable para los ciudadanos, bien porque ello necesitaría consigo el transcurso de un lapso de tiempo, la realidad es que ni siquiera en el orden teórico ha habido una clara postura de oposición frontal al derecho de sucesión.

En estos momentos en que las doctrinas socioeconómicas imperantes en el mundo occidental son de un encendido - y excesivo - neoliberalismo, no parece chocante que el testamento no sea como tal impugnado doctrinalmente; lo que llama la atención es que a lo largo de la historia ${ }^{33}$ el derecho de sucesión haya recibido menos críticas que el derecho de propiedad a pesar de que aquél es la forma clásica de acumulación de éste.

En cualquier caso el reconocimiento del derecho a la sucesión es un dato meta jurídico que se le impone al derecho.

Será la filosofía política del derecho la que la admita o lo rechace y el jurista debe trabajar a partir de los datos que se le ofrecen, aunque como queda dicho la tónica universal en la práctica legislativa es el de su admisión con mayores o menores recortes.

\section{2. ${ }^{\circ}$ Límites}

Admitiendo el derecho de sucesión, el problema queda en fijar los límites del mismo, ya que casi todos los ordenamientos jurídicos continentales admiten la existencia de las legítimas o parte de la herencia que forzosamente deben ir a parar a manos de determinados herederos (normalmente los descendientes, y en su caso el cónyuge).

Por ello, y partiendo de la legitimidad de la sucesión, cabe decir que la actitud del legislador frente al hecho testamentario puede ser triple:

a) Desconocer el principio de la admisibilidad del testamento prohibiéndolo totalmente como sucedió en los ordenamientos del Antiguo Oriente.

33 La mayoría de los países de regímenes comunistas aceptaron el derecho de herencia y de testamento, así sucedió en el Código Civil de la extinta Unión Soviética que reguló la herencia ( $\$ 416$ y siguientes) y el testamento ( $\$ 418$ ). No obstante hay que reconocer que el Código Civil Soviético ponía unos topes a la cuantía de la sucesión. 
b) Admitir la libertad de testar pero siempre que la misma esté dentro de determinados parámetros que la ley señala. Este camino intermedio es el que con mayor o menor rigor han seguido la mayoría de los ordenamientos actuales de tipo romano-germánico.

DERNBURG $^{34}$ señala que las disposiciones que en materia hereditaria contienen las distintas legislaciones es el promedio de los casos según el sentir nacional, aunque en algunos supuestos no corresponda a las particulares relaciones y necesidades individuales.

La vía para lograr este objetivo es doble: por una parte indicar unos herederos a los cuales hay que dejar forzosamente un mínimo que señala la legislación respectiva, y por otra, indicar que tales personas no podrán ser desheredadas sino por los casos que la propia legislación señala.

c) Reconocer la facultad de testar de manera omnímoda o casi pudiendo el testador dejar los bienes a quien estimara oportuno, como sucede en general en el derecho anglosajón.

El derecho inglés adopta el principio de la libertad de la disposición del testador, aunque de acuerdo con las modificaciones que a partir de 1938 introdujeron diversas leyes se faculta al tribunal para poder fijar unos límites, o para modificar el orden legal, cuando el testador no hizo una disposición testamentaria a favor del cónyuge supertite o a favor de los hijos del testador.

Dentro de nuestro ordenamiento jurídico el Fuero de Ayala prevé una libertad absoluta de testar.

La admisión de una mayor o menor libertad de testar ha dependido fundamentalmente de la tradición jurídica de cada país o de cada sistema: normalmente la doctrina no ha polemizado sobre las ventajas de uno u otro sistema. Lo que es evidente es que la libertad de testar potencia el testamento y los deseos del testador, mientras que el sistema legal da más importancia a la protección de los familiares ${ }^{35}$.

34 Das bürgerliche Recht, citado por TRAVIESAS, obra citada, p. 98.

35 Ciertamente cada opción tiene ventajas e inconvenientes, no se ve por qué, por ejemplo, un futbolista que ha obtenido un cuantioso patrimonio con la práctica del deporte, no pueda dejar la mayor parte de éste, a un sobrino con quien convivió y que le atendió en vez de a unos hijos que lo han abandonado y con los que no ha tenido ninguna relación desde hace muchos años, pero, cogiendo otro ejemplo no parece admisible que una elevada fortuna personal que se ha transmitido dentro de la familia durante generaciones pase, debido al capricho momentáneo y a la ofuscación del testador a una persona totalmente ajena a la familia. Como cualquier solución que se adopte ha de ser general es evidente que ambas tienen sus ventajas y sus inconvenientes, aunque tal vez la vía intermedia que dé trascendencia a la voluntad del testador, pero que le imponga unos ciertos límites, sea la más adecuada. A tal efecto cabe decir que el Código Civil es demasiado rígido con el tratamiento de las causas de desheredación. 


\section{Naturaleza jurídica}

¿Cuál es la naturaleza jurídica del testamento?

Por algún sector doctrinal se ha tratado de negar el carácter de negocio del testamento alegando que no produce de entrada efecto alguno y que es algo interno o un mero proyecto ${ }^{36}$, ya que no se hace nada más que para cuando se produzca el fallecimiento del causante que la complementa, y así ha colocado al testamento entre los negocios jurídicos unilaterales o imperfectos cuya actuación se complementa con la muerte del causante, siendo, para un sector doctrinal, negotiun imperfectum en tanto que el causante viva sin producir ningun efecto jurídico.

JosSERAND ${ }^{37}$ señala que hasta la muerte del testador el testamento no es más que un mero proyecto que puede ser revocado ad nutum por el que lo ha otorgado; y DE BUEN ${ }^{38}$ incide también en que el testamento es sólo un proyecto que alcanza el carácter definitivo el día de la muerte del testador.

Tales alegaciones son ciertas pero no obstante las mismas hay que señalar, como subraya PUIG PEÑA ${ }^{39}$, que no puede decirse que la voluntad testamentaria sea interina o provisional, ya que cuando el testador emite una declaración formal de voluntad en el testamento lo hace con carácter definitivo y vinculante para después de su fallecimiento, lo cual no impide que con el transcurso del tiempo pueda cambiar de orientación y revocar el primer testamento.

KOHLER $^{40}$ señala que el causante es inmediatamente antes de hacer el testamento un testatus aunque no exista todavía una inmediata donación de herencia, de la misma manera que en la emisión de la ley existe un acto jurídico perfecto, aún cuando la ejecución de la misma sea aplazada.

En cualquier caso existen negocios jurídicos sometidos a término o condición que dependen para la producción de efectos de que transcurra un tiempo determinado o de que se dé determinada condición: y nadie sostiene que tales negocios no son perfectos y definitivos.

Finalmente no hay que olvidar que el testamento produce efectos que no son revocables como pudieran ser la revocación del testamento anterior o el reconocimiento de hijos.

36 Puig PeÑa. Tratado de derecho civil español, tomo V, volumen I, Madrid 1954, pp. 91 y ss.

37 Cours de droit civile, tomo III, París 1930, p. 849.

38 Derecho Civil, tomo II, Madrid 1932, p. 398.

39 Obra citada, p. 92.

40 Ademtion der legate, en Zeitschrif de Grünhut, VII, pp. 734 y 735. Citado por TRAVIESAS, obra citada, p. 101. 
Por todo ello la doctrina actual se muestra prácticamente concorde en entender el carácter de negocio jurídico del testamento ${ }^{41}$; y también el Tribunal Supremo lo ha entendido así1 ${ }^{42}$ : tal conceptuación tiene la consecuencia lógica e importante de ser aplicable al testamento la doctrina general de los actos y negocios jurídicos ${ }^{43}$.

La determinación del momento que el testamento se perfecciona es importante y concretamente la determinación de si se perfecciona en el momento de la emisión solemne de la declaración de voluntad del testador o en el de la muerte de éste ${ }^{44}$.

El problema deriva de que, como apunta $\mathrm{CICU}^{45}$, en la terminología corriente el negocio perfecto o la perfección existe cuando tiene todos sus elementos constitutivos y aparentemente al testamento le podía faltar uno, esto es, el del fallecimiento del testador porque hasta tal momento no produce efectos.

Pero como continúa el propio Cicu la claridad la ofrece la comparación de la revocación del testamento - el escollo fundamental a su perfección porque si no, no habría diferencia entre el testamento y un negocio jurídico a término o condición-: otros negocios jurídicos también son revocables por el común acuerdo de los contratantes. Tal doctrina es aplicable al testamento con la única diferencia que se deriva de su naturaleza, esto es, que al ser un negocio jurídico unilateral no hará falta nada más que la voluntad del testador para revocarlo; y si no hay revocación el testamento será perfecto y producirá sus efectos post

41 Albaladejo, obra citada, p. 101; Díez Picazo y Gullón, Sistema de Derecho Civil, vol. IV, Madrid 1990, p. 352; KIPP en EnNeCCERus, Tratado de Derecho Civil, tomo V-Derecho de Sucesiones, p. 69; Jordano Barea, obra citada, p. 1679; Lledó YagüE, Derecho de Sucesiones, Bilbao 1991, vol. II, primera parte, p. 267; y PUIG PEÑA, obra citada, pp. 91 y ss.

${ }^{42}$ S. 24 de noviembre de 1958, Ar. 3.800 y 8 de julio de 1940, Ar. 689 la cual señala: «se desprende inequívocamente que se trata de un acto o negocio jurídico, que tiene como elemento esencial una declaración de voluntad, sujeta a todas las reglas generales concernientes a las manifestantes de voluntad con efectos jurídicos y que, ante todo y sobre todo, exige y presupone una voluntad expresada en forma suficientemente inteligible».

Observemos no obstante que el testamento no es una declaración de voluntad recepticia y que como señalan La CRUz Berdejo y SÁnchez Rebullida (Derecho de sucesiones, tomo I, Barcelona 1971, p. 352) el notario y los testigos, en su caso, reciben la declaración a los solos efectos documentación y testimonio.

43 No obstante la doctrina (al menos la española) y la jurisprudencia no ha insistido bastante en este punto que es fundamental para la validez y existencia del testamento, cual es la de considerarle un negocio jurídico y serle aplicable los principios generales que rigen a éstos.

44 Según Puig Brutau, Fundamentos de Derecho Civil, tomo V, vol. II, Barcelona 1977, p. 8, tanto para CICU como para JORDANO «testamento y aceptación son dos negocios distintos y autónomos».

45 Obra citada, p. 21. 
mortem con independencia de las vicisitudes que en su estado mental, situación, etc., sufra el testador el resto de su vida.

En definitiva, y como concluye $\mathrm{CiCu}^{46}$, la muerte no es el elemento que perfecciona el testamento sino el que determina la producción de sus efectos jurídicos: ahora bien en cualquier caso la decisión de otorgar testamento debe ser una decisión firme, cumpliendo las formalidades legales y no un mero proyecto.

Por eso el Tribunal Supremo ha tratado de diferenciar los proyectos o esbozos de los verdaderos testamentos, insistiendo en que los que no son un acto definitivo, sino proyectos, en los que no conste claramente la voluntad de testar, no son testamento ${ }^{47}$, precisando que:

«Que al ser esencialmente el testamento un acto dispositivo de bienes o derechos, no es verdadero testamento el acto que, aun presentando la forma externa de tal, pueda dudarse si constituye un simple esbozo o proyecto y no un acto definitivo, o en que el otorgante se limite a aconsejar o rogar respecto al destino de su patrimonio; sin que esto quiera decir que el carácter imperativo de las disposiciones haya de colegirse únicamente de la literalidad de las expresiones que se empleen. Segunda. Que siendo el testamento, acto por el que alguno dispone para después de su muerte, no valdrá como tal si no consta con claridad la intención de testar, esto es, de disponer para después de la muerte del declarante. Tercera. Que si bien, en síntesis, es indiferente el modo y términos con que el testador se exprese, siempre es necesario la esencia de la disposición "mortis causa" en sus palabras.»"

En cuanto al carácter del testamento se ha discutido sobre si el mismo debe ser personalísimo; y dentro de nuestro ordenamiento jurídico parece debe entenderse así a tenor del artículo 670 del Código Civil que señala que el mismo es un acto personalísimo y que no puede dejarse su formación en todo ni en parte al arbitrio de terceros.

Eso significa que el testamento no solamente ha de reflejar la voluntad del testador sino además que no debe contener más voluntad que la suya ${ }^{49}$.

De entrada hay que hacer constar que, según señala OSORIO SERRANO ${ }^{50}$, es intrascendente indicar quién puede ser considerado como tercero a

46 Obra citada, pp. 5 y ss.

47 S. 30 de diciembre de 1958, Ar. 3.800.

48 S. 8 de julio de 1940, Ar. 689.

49 Véase Cicu, obra citada, p. 24.

50 «Comentario al artículo 670 del Código Civil» en Comentarios al Código Civil y compilaciones forales, dirigidos por Manuel AlbaladEJo, vol. IX, citado, p. 132. 
los efectos de lo que aquí se prohíbe, porque fuera cual fuese la persona designada sería tercero, dado que lo que el Código desea es resaltar y exigir el carácter personalísimo del testamento y todo lo que a él no se acomode será intervención de un tercero.

Ciertamente y como señala el propio OsORIo SERRANo ello no excluye la posibilidad de solicitar la ayuda material de otra persona en el momento de redactar el testamento, ni tampoco el consejo y asesoramiento previo.

Pero todo ello nada obsta a la imposibilidad legal de pedir a un tercero que haga o complete el testamento realizado en nombre del causante.

Por otro lado, señala OSORIO SERRANO ${ }^{51}$ que la prohibición legal se desdobla en dos, una relativa al momento de la formación del testamento en virtud de la cual no puede encomendar a otro la efectiva realización del testamento (párrafo $1 .^{\circ}$ ) y otro relativa a la ejecución del mismo, una vez ya hecho, según la cual no puede dejarse al arbitrio de tercero la subsistencia del nombramiento de herederos o legatarios (párrafo $2 .^{\circ}$, todo ello con la misión de preservar el carácter personalísimo y unipersonalísimo - artículo 670-2. ${ }^{\circ}$ - del testamento.

El Tribunal Supremo señala comentando el artículo 670 del Código Civil que:

«... desde el momento que el testamento es un acto personalísimo y que por tanto ni puede dejarse su formación, en todo ni en parte, al arbitrio de un tercero, ni hacerse por medio de comisario o mandatario, ni dejarse al arbitrio de un tercero la subsistencia del nombramiento de herederos o legatarios, ni la designación de las porciones en que hayan de suceder cuanto sean instituidos nominalmente, según establece el artículo 670 del Código Civil, que evidentemente se vería vulnerado de autorizarse que un cónyuge alterase la voluntad testamentaria establecida por su cónyuge premuerto, dando por pagados, por entrega de bienes que el primero dice haber efectuado al causante de los demandantes reconvenidos, la herencia que del segundo les correspondía.» ${ }^{52}$

Es de señalar que en nuestro ordenamiento jurídico, anterior al Código Civil, el testamento por comisario sufrió diversas vicisitudes, ya que inicialmente no estaba permitido ni por el derecho romano ${ }^{53}$ ni por

51 Obra citada, p. 137.

52 S. 29 de febrero de 1992, Ar. 1.407.

53 Digesto 28.5.32. indica

La institución de «los que quisiese Ticio» es viciosa porque se deja al arbitrio ajeno, ya que bien claramente dejaron establecido los antiguos que los derechos testamentarios deben valer por sí mismo y no depender del arbitrio ajeno. Se instituye válidamente heredero al que 
las Partidas ${ }^{54}$. Pero el derecho posterior a éstas lo admitió, aunque ulteriormente de nuevo fue prohibido por el Código Civil, aun cuando no así por las distintas compilaciones forales, ya que en Aragón se admite la llamada fiducia sucesoria ${ }^{55}$, en Baleares se prevé el llamado heredero distribuidor ${ }^{56}$, en Navarra las leyes 281 y siguientes regulan la institución de fiduciario comisario, y en Vizcaya la Ley 3/92 de 1 de junio del Parlamento Vasco, regula el testamento mancomunado o de hermandad ${ }^{57}$ otorgado entre cónyuges, extendiéndolo incluso a los vizcaínos no aforados de acuerdo con el artículo 13 de la misma Ley.

En cuanto a la admisión o no del testamento por comisario las posturas han sido encontradas, habiéndose mantenido por la mayoría de la doctrina civilista próxima, cronológicamente, a la promulgación del Código Civil, lo acertado de la prohibición ${ }^{58}$, y se ha sostenido que así se evita un actuar caprichoso y se disminuyen los pleitos y enfrentamientos. Por otro lado, otro sector doctrinal, particularmente foralista ${ }^{59}$ ha mantenido la virtualidad de esta figura jurídica, que según él es acaso la más típica institución de derecho civil de Vizcaya ${ }^{60}$, y ha sostenido que por el hecho de que algún comisario pueda hacer un uso indebido de los poderes, no se puede descalificar la institución. Ciertamente las actuaciones incorrectas de algún comisario no es argumento suficiente para prohibir esta figura jurídica, del mismo modo que el uso indebido que puedan hacer algunos tutores de sus facultades no son suficientes para eliminar la figura del tutor. Porque el que haya actuaciones caprichosas e inmotivadas por parte de algún comisario ni siquiera significa que no las pudiera haber incluso por parte del mismo testador: en definitiva dependerá de la cordura tanto del comi-

está en poder de los enemigos, porque retiene en suspenso, por derecho de postliminio, todos los derechos civiles, sin perderlos, y por tanto, si regresase del enemigo, podrá aceptar la herencia. También su esclavo puede ser válidamente instituido heredero, $\mathrm{y}$, si el dueño regresase del enemigo, podrá mandarle que lleve a cabo la adición de la herencia, más si muriese en el cautiverio, puede adquirir la herencia por medio del esclavo el que fuese su heredero.

54 Ley 11, título III, partida 6. ${ }^{\text {a }}$ : Como el testador debe nombrar por sí mismo a aquel que establece por heredero et non ponerlo en albedrio deotri: Declarar debe et nombrar el facedor del testamento por si mesmo el nombre de aquel que establece por heredero; ça si otorgare poder a otro que lo estableciese en su lugar non valdria ... et esto es porque el establecimiento del heredero et de las mandas non debe ser puesto el albedrio de otro.

55 Arts. 114 y 115 de la Ley 15/67.

56 Art. 18 del Texto Refundido de la Compilación de Derecho Civil de las Islas Baleares.

57 Arts. 49 y ss. de la Ley 3/92.

58 Manresa, obra citada, pp. 443 y ss. Mucius Scheaevola, Código Civil, tomo XII, Madrid 1896, p. 74.

59 Así Celaya Ibarra, El testamento por comisario, ADC 1972, pp. 746 y ss.

60 Celaya Ibarra, en «Comentarios a la compilación de Vizcaya y Alava» en Comentario al Código Civil y compilaciones forales, dirigidos por Manuel AlBALADEJo, Madrid 1978, p. 152. 
sario como del testador al elegirle, pero esa mayor cordura y sensatez son aplicables no solamente a la institución comentada, sino a otras muchas figuras jurídicas; señalando por último que, en muchos casos, dejar la decisión definitiva para un momento ulterior puede reportar claras ventajas.

En conclusión el poder testatorio, inválido en nuestro ordenamiento jurídico común y en otros, como queda expuesto, es admitido en numerosas ocasiones por los ordenamientos forales; y por tanto la no realización del testamento por medio de tercero, puede ser propugnada como característica del testamento otorgado en territorios de derecho común, pero no es válida en gran parte de los que están regidos por los distintos derechos forales.

En los territorios de derecho común el Tribunal Supremo ha sido tajante en mantener la imposibilidad de otorgar el testamento por medio de tercero:

«... el testamento es un acto personalísimo, que como de tal naturaleza no posibilita que se deje su formación, en todo ni en parte, al arbitrio de un tercero, ni hacerse por medio de mandatario, como tampoco que lleven éstos a cabo el nombramiento de herederos, ni la designación de las porciones en que hayan de suceder cuando sean instituidos nominalmente, como consecuencia, según indica la sentencia de esta Sala de 20 mayo 1972 de haber recogido dicho artículo 670 el principio romano del carácter personalísimo del testamento, de larga y constante tradición en nuestro derecho, apenas alterado por el Fuero Real, que fue objeto de subsiguientes limitaciones hasta su definitiva derogación ${ }^{61}$.»

El Tribunal Supremo ha recordado que no puede dejarse la designación de legatarios al arbitrio de un tercero ${ }^{62}$ y que tampoco cabe el dejar a elección de éste, la designación de las porciones en que hayan de suceder los herederos ${ }^{63}$ o incluso que no cabe que el testador facultara a su mujer para que realice en representación de la testamentaría todo aquello que crea conveniente e incluso anular un legado ${ }^{64}$.

Pero la premisa de carácter imperativo que defiende el Código Civil nos lleva más lejos que la prohibición del testamento mancomunado que contiene el artículo 669; es más, en algunos casos podría decirse que la prohibición del artículo 670 puede extenderse a los testamentos mancomunados de forma que ellos sean también actos exclusivos de las dos personas que lo otorgan y de nada más que ellos. Y es que la

61 S. 30 de mayo de 1978, Ar. 1.953.

62 S. 26 de marzo de 1958, Ar. 2.511.

63 S. 4 de febrero de 1975, Ar. 4.324.

64 S. 31 de diciembre de 1931, Ar. 2.333. 
vía del artículo 670 nos conduce por un camino difícil, ya que es complicado distinguir cuáles son los consejos legítimos que el testador pueda recibir, y no sólo en el aspecto jurídico, sino en el aspecto económico e incluso personal de juristas, técnicos o de familiares, de los supuestos en que la voluntad del testador es guiada por otra diferente que puede ser, en muchos o en algunos casos, interesada.

El artículo 670 del Código Civil prohíbe la intervención del tercero en la redacción del testamento de una forma clara, tajante y rotunda, ya que el párrafo segundo señala cómo no puede dejarse al arbitrio del tercero la subsistencia del nombramiento de herederos o legatarios, ni la designación de las porciones en que hayan de suceder cuando se han instituido nominalmente, con lo cual, recalca más que otros ordenamientos el carácter personal del testamento ${ }^{65}$.

65 Por ejemplo el artículo 2.182. ${ }^{\circ}$ del Código Portugués manifiesta:

1. O testamento é acto pessoal, insusceptível de ser feito por meio de representante ou de ficar dependente do arbítrio de outrem, quer pelo que toca à instituiçao de herdeiros ou nomeaçao de legatários, quer pelo que respeita ao objecto da herança ou do legado, quer pelo que pertence ao cumprimento ou nao cumprimento das suas disposiçoes.

2. O testador pode, todavía, cometer a terceiro:

a) A repartiçao da herança ou do legado, quando institua ou nomeie uma generalidade de pessoas;

b) A nomeaçao do legatário de entre pessoas por aquele determinadas.

3. Nos casos previstos no número antecedente, qualquer interessado tem a faculdade de requerer ao tribunal a fixaçao de um prazo para a repartiçao da herança ou do legado ou nomeaçao do legatário, sob a saminaçao, no primeiro caso, de a repartiçao pertencer à pessoa designada para o efeito pelo tribunal e, no segundo, a distribuiçao do legado ser feita por igual pelas pessoas que o testador tenha determinado.

Como puede verse, el código portugués admite, al menos en parte, la intervención de un tercero en la designación de legatario, aun manteniendo el carácter personal del testamento.

En parecido sentido el artículo 631 del Código Civil italiano señala:

Disposizioni rimesse all'arbitrio del terzo. É nulla ogni disposizione testamentaria con la quale si fa dipendere dall' arbitrio di un terzo l'indicazione dell'erede o del legatario, ovvero la determinazione della quota di eradità.

Tuttuvia è valida la disposizione a titolo particolare in favore di persona da scegliersi dall'onerato o da un terzo tra più persona determinte dal testatore o appartenenti a famiglie $o$ categorie di persone da lui determinate, ed è pure valida la disposizione a titolo particolare a favore di uno tra più enti determinati del pari dal testatore. Se sono indicate più persone in modo alternativo e non è stabilito chi deve fare la scelta, questa si considera lasciata all'onerato.

Se l'onerato o il terzo non può o non vuole fare la scelta, questa è fatta con decreto dal presidente del tribunale del luogo in cui si è aperta la successione dopo avere assunto le opportune informazioni.

En cambio el artículo 3.619 del Código argentino es tajante en el carácter personalísimo del testamento:

Las disposiciones testamentarias deben ser la expresión directa de la voluntad del testador. Este no puede delegarlas ni dar poder a otro para testar, ni dejar ninguna de sus disposiciones al arbitrio de un tercero. 
Lo que si cabe es que el testador confiara a un tercero, de acuerdo con el texto del artículo 671 del Código Civil la distribución de las cantidades que deje en general a clases determinadas, como los parientes, a los pobres, o a los establecimientos de beneficiencia, así como la elección de las personas o establecimientos a quienes deban aplicarse.

Tal normativa constituye una contravención a la prohibición general contenida en el artículo 670 y así se ha señalado por la doctrina ${ }^{66}$. No obstante señala OSORIO SERRANO ${ }^{67}$ que la distribución de cantidades a que alude el artículo 671 es lo mismo que la distribución de porciones y por tanto dicho precepto no hace nada más que ratificar la regla del artículo 670 que señala que no podrán dejarse al arbitrio de un tercero la designación de las personas en que hayan de suceder cuando se han instituido nominalmente; de donde concluye que, a sensu contrario, el Código Civil admite la indicación de las porciones en que hayan de suceder por parte de tercero cuando no sean instituidos nominalmente los herederos.

No obstante, lo que no parece justificable a priori es el por qué se tiene que prohibir al testador el que encomiende a otra persona la designación de los herederos, instituidos nominalmente, y se admite cuando los herederos no sean instituidos de tal forma. Podría pensarse que los instituidos de forma genérica como clases determinadas pueden ser instituciones de beneficiencia o entidades análogas, con menor trascendencia habitualmente tanto en el porcentaje de la herencia como en la concreción de la entidad cualquiera. Pero razonando de tal forma se olvida qué clase de personas, según el propio Código señala, son los parientes, cuya determinación reviste una trascendencia excepcional; y que, además, tampoco es baladí determinar qué institución benéfica heredará. Por eso no me parece correcta la prohibición legal en un supuesto y no en otro; pero a pesar de ello el texto legal es claro al respecto.

La prohibición de intervención de un tercero en el testamento nada tiene que ver con la institución condicional de heredero que es admitida en los artículos 788 y, sobre todo en el 790 y siguientes del Código Civil.

El testamento es un acto de voluntad que regula la sucesión voluntaria y a tal voluntad hay que dar fundamentalmente valor ya que es la ley de la sucesión cuanto se trata de sucesión hereditaria, como ha resaltado el Tribunal Supremo:

66 Por todos DíEz PicAzo, El arbitrio de un tercero en los negocios jurídicos, Barcelona 1957 , pp. 160 y ss.

67 Obra citada, p. 146. 
«No conviene olvidar que de la materia sucesoria la voluntad testamentaria es soberana dentro de los límites de la legalidad y toda actividad judicial interpretativa ha de orientarse en la búsqueda y precisión de la voluntad real del causante, al tratarse de declaraciones no recepticias que se manifiestan en forma totalmente unilateral, por lo que no sucede, como en los negocios contractuales, que haya de tenerse en cuenta los intereses y voluntades de otras partes, que no son precisamente contrapartes testamentarias. Cuando como ocurre en este caso, la literalidad de la cláusula se presente suficientemente expresiva y diáfana, ha de estarse a la misma y así la Sala de Apelación observó con todo acierto dicha regla, sin necesidad de acudir a actividades exegéticas respecto a otras disposiciones, ni a los llamados medios de prueba extrínsecos (Sentencias de 11 diciembre 1991, 6 abril 1992 y 31 diciembre 1992, entre otras) $)^{68}$.»

El Tribunal Supremo ha señalado con justeza la importancia del testamento como expresión de la voluntad del testador que debe ser la ley de la sucesión salvo los supuestos especiales en los que se infrinjan los límites legales.

En conclusión, el testamento es uno de los negocios jurídicos que aunque sean menos numerosos - una persona podrá hacer cientos en su vida pero sólo uno de ellos producirá efectos después de su fallecimiento ${ }^{69}$ tiene más trascendencia por el carácter universal de la sucesión por referirse a todo el patrimonio del testador y por los efectos duraderos que puede producir.

68 S. 1 de marzo de 1995, Ar. 1.769.

69 Ciertamente podrá haber aspectos del testamento derogado que produzcan efectos, como pudiera ser el reconocimiento de hijo de acuerdo con el artículo 741 del Código Civil. La sentencia de 7 de mayo de 1990, Ar. 3.687 señala que:

«Superado un primitivo criterio rigorista de ineludible exigencia de que la voluntad del testador en el indicado sentido había de aparecer explícita y formalmente expresada en el testamento posterior, sin cuyo requisito en ningún caso podía pervivir total o parcialmente el anterior, el nuevo y más flexible criterio jurisprudencial, ya iniciado en las Sentencias de esta Sala de 22 marzo 1901, 17 junio 1915 y 11 diciembre 1929, y consolidado en la reciente de 1 febrero 1988, coincidente, además con el de la doctrina científica mayoritaria y con el que ya adoptó la Dirección General de los Registros y del Notariado (Resoluciones de 12 setiembre 1947 y 18 diciembre 1951) es el de que la "voluntad" que se exige en el párrafo primero del artículo 739 del Código Civil para dejar subsistente un testamento anterior puede ser no sólo la explícita o expresa en tal sentido, sino también la que se deduzca del tenor de ambos testamentos cuando, aplicando las reglas de interpretación que establece el artículo 675 del mismo Cuerpo legal, aparezca evidente 1a intención del testador de mantener o conservar el testamento anterior, respecto del cual el posterior sea complementario, aclaratorio o simplemente modificativo». 